\title{
Mundos aislados: segregación urbana y desigualdad en la ciudad de México*
}

\author{
GONZALO A. SARAVÍ \\ **Profesor investigador del Centro de Investigaciones y Estudios Superiores en Antropología Social (CIESAS), \\ México.
}

\begin{abstract}
What does urban segregation mean in Mexico and what are its implications for this particular context? This article poses these two questions. Our response is based on the hypothesis of the "co-existence of isolated worlds." In order to support and develop this hypothesis, the author analyses the relationship between the objective and symbolic dimensions of urban segregation. The analysis is based on secondary data and semi-structured interviews with young people from poor and stigmatized neighborhoods in Mexico City.
\end{abstract}

Keywords: urban segregation, social inequality, urban sociability, stigma.

RESUMEN De qué nos habla la segregación urbana en México y cuáles son sus implicaciones en este contexto en particular, son las dos preguntas centrales que guían el análisis desarrollado en este artículo. El argumento que responde a estas dos preguntas se estructura en torno a la hipótesis de una "coexistencia de mundos aislados". Para sustentar dicha hipótesis, el autor analiza teórica y empíricamente la relación entre las dimensiones objetiva y simbólica de la segregación urbana. El análisis se basa en datos secundarios y en información obtenida a partir de entrevistas semi-estructuradas con jóvenes residentes en colonias populares y estigmatizadas de la Ciudad de México.

Palabras claves: Segregación urbana, desigualdad social, sociabilidad urbana, estigmas.

\footnotetext{
* El proyecto de investigación "Juventud, desigualdad y exclusión en México" ha sido desarrollado por el autor de este artículo como parte de sus tareas de investigación en el CIESAS durante el período 2003-2007. Los principales resultados de dicha investigación se encuentran en el libro: "Transiciones Vulnerables", actualmente en prensa por la editorial del CIESAS. En 2008 el autor recibió financiamiento del Consejo Nacional de Ciencia y Tecnología (CONACyT) para la continuidad de esta investigación, en una nueva etapa que incluirá jóvenes de diferentes estratos sociales para focalizar el análisis sobre los impactos de la desigualdad en la cohesión social.
}

Recibido el 23 de septiembre de 2008, aprobado el 21 de noviembre de 2008.

Correspondencia: Gonzalo Saraví, Juárez 87, Col. Tlalpan Centro, Del. Tlalpan. C.P. 14000, México D.F. México. Fono: (52-55) 5487-3600. Fax: (52-55) 5487-3643. E-mail: gsaravi@ciesas.edu.mx. 


\section{Introducción}

La exploración de los procesos de segregación urbana y de sus repercusiones sobre diversos ámbitos de la vida social, plantea de manera casi inevitable la necesidad de un ejercicio analítico respecto a las vinculaciones entre la estructura espacial y la estructura social. Aunque pueda parecer paradójico, en muchos de los estudios sobre segregación urbana este ejercicio previo permanece ausente, con lo cual asumen un fuerte carácter descriptivo, no sólo desprovistos del esfuerzo interpretativo necesario, sino que además dejan al lector con más datos pero con la misma incertidumbre inicial respecto a cuáles son sus implicaciones. Los múltiples indicadores hoy existentes de segregación pueden tener no sólo significados muy disímiles, sino que incluso pueden dar lugar a interpretaciones contrastantes dependiendo del contexto urbano (y nacional) al que hagan referencia. Como lo ha señalado Sabatini (2003), la segregación urbana no se asocia necesariamente con desigualdad, ni tiene irremediablemente consecuencias negativas, por lo cual es necesario ir más allá y explorar sus significados e implicaciones sin asumir por dados los supuestos del sentido común.

Resulta necesario entonces insertar dichos indicadores y mediciones en un marco teórico interpretativo, que permita darles sentido, y proveer una lectura específica de la realidad social en un contexto particular. El análisis de la segregación urbana no puede desentenderse del contexto socio-histórico en el que se inserta, y a la vez debería contribuir a echar luz sobre ciertos procesos sociales en curso. El objetivo de este artículo consiste precisamente en explorar las particularidades que adquiere la segregación urbana en la Ciudad de México, pero desde una perspectiva interpretativa. Esto significa que más allá de los distintos indicadores estadísticos que puedan brindarse, la pretensión es construir un marco interpretativo que permita darles sentido en términos de la estructura social y espacial de la ciudad.

El propósito central del análisis que presento aquí consiste en responder a las preguntas: ¿De qué nos habla la segregación urbana en México? Y ¿cuáles son sus implicaciones en este contexto en particular? Esto me condujo a privilegiar dos temas: el de "la sociabilidad urbana" y el de "la dimensión simbólica de la segregación". En el siguiente apartado introduzco estas dos ideas, luego de argumentar la importancia de identificar y explorar los ejes claves en torno a los cuales se organiza la estructura social y espacial en un contexto urbano en particular. En el tercer apartado utilizo estas dos ideas para comenzar a construir una interpretación del sentido de la segregación urbana en la Ciudad de México, y en el apartado siguiente se pone a prueba esta interpretación a partir de un análisis de los estigmas territoriales. Finalmente en las conclusiones planteo que la coexistencia de mundos aislados se constituye en una interpretación que permite responder a las preguntas previas, pero que al mismo tiempo deja ver las tensiones que enfrenta la cohesión social en un contexto de profunda desigualdad.

El análisis se basa tanto en datos secundarios, como en información obtenida a partir de entrevistas realizadas con jóvenes residentes en tres colonias populares y altamente estigmatizadas de la Zona Metropolitana de la Ciudad de México, en el marco del proyecto "Juventud, 
Desigualdad y Exclusión en México" ${ }^{1}$. Dicho proyecto tuvo como objetivo principal explorar los factores de riesgo en el proceso de transición a la adultez en jóvenes de sectores populares. La segregación urbana de sus áreas de residencia fue uno de los factores sobre los que se concentró la investigación, por lo cual si bien las entrevistas no estuvieron exclusivamente focalizadas sobre este tema, incluyeron una batería de preguntas que pretendían indagar la presencia, percepciones y efectos de los estigmas territoriales sobre sus colonias. Los argumentos desarrollados en este artículo son parte de los resultados de dicha investigación sobre este tema en particular.

\section{Segregación urbana, diferenciación social y sociabilidad}

La segregación espacial urbana puede entenderse como una dimensión específica de un proceso general de diferenciación social (Barbosa, 2001), y en este sentido es posible reconocer múltiples criterios a partir de los cuales puede tener lugar. Sin embargo, la relación resulta aún más densa si entendemos que la división social del espacio urbano es una representación espacial que, si bien no agota, es reflejo de la estructura social. Es decir, no se trata de una diferenciación casual, ahistórica, o natural, sino que ella deja leer los cortes y clivajes que atraviesan y dan forma a la estructura social. Tal como señala Bourdieu:

"Así, la estructura del espacio se manifiesta, en los contextos más diversos, en la forma de oposiciones espaciales, en las que el espacio habitado (o apropiado) funciona como una especie de simbolización espontánea del espacio social. En una sociedad jerárquica, no hay espacio que no esté jerarquizado y no exprese las jerarquías y las distancias sociales, de un modo (más o menos) deformado y sobre todo enmascarado por el efecto de naturalización que entraña la inscripción duradera de las realidades sociales en el mundo natural: así, determinadas diferencias producidas por la lógica histórica pueden parecer surgidas de la naturaleza de las cosas" (Bourdieu, 2002, p. 120).

Uno de los ejes más importantes y críticos de diferenciación en la sociedad contemporánea, y en particular en la mexicana, es la diferenciación de la población según su condición socioeconómica. Es en este sentido que "la división social del espacio tiene como componente fundamental la característica de ser la expresión espacial de la estructura de clases o de la estratificación social" (Duhau, 2003a, p. 179). Es decir, si bien existen muchos posibles criterios de diferenciación social que a su vez podrían verse expresados en la estructura espacial, en una sociedad donde cobra una preeminencia absoluta la condición socio-económica para posicionar a los sujetos en la estructura social, esta preeminencia se ve reflejada en el espacio urbano.

Este es un primer aspecto particularmente relevante. No se trata simplemente de un criterio de diferenciación, sino al mismo tiempo de un criterio clave de jerarquización, y más específicamente de desigualdad. Cuando hablamos entonces de la distribución de la población en el espacio, del nivel de concentración de determinados grupos en ciertas áreas de la ciudad,

1 Se realizaron en total 38 entrevistas semiestructuradas, en dos etapas: 21 a fines de 2003 en colonias vecinas del Iztapalapa y Nezahualcoyotl, y otras 17 a inicios de 2006 en una colonia de Valle de Chalco. 
y/o del grado de homogeneidad social que presentan áreas específicas; hablamos no sólo de diferenciación sino también de desigualdad, e incluso tal vez de exclusión. Tal como lo señala Barry (2002), niveles de alta desigualdad como los que caracterizan a América Latina (según el ejemplo puesto por el propio autor) pueden conducir a la fragmentación de la sociedad como consecuencia del aislamiento de los sectores privilegiados y la exclusión de los más desfavorecidos. También García Canclini (2005), en uno de sus trabajos más recientes, señala que la diferenciación, la desigualdad, y la desconexión no son términos ni procesos intercambiables, pero que sin embargo con frecuencia se encuentran no sólo entrelazados sino incluso superpuestos. Esta potencial superposición puede hacer que en algunas ocasiones los tres fenómenos resulten indistinguibles para el ojo ingenuo, pero eso no debería conducir a pasar por alto en el momento analítico no sólo la especificidad de cada uno de ellos, sino tampoco la particularidad que asume la diferenciación, la desigualdad, y/o la exclusión cuando se superponen entre sí.

El análisis de la segregación espacial urbana nos dirá entonces cosas muy distintas según cómo se entrelacen estos tres procesos. La estructura del espacio urbano no puede ser cabalmente entendida ni explotada en sus potencialidades analíticas si no se la interpreta como la distribución en el espacio de actores socialmente posicionados. Llegados a este punto podemos tener algunas ideas más claras respecto a los potenciales temas de los que nos pueden hablar los estudios sobre segregación espacial urbana y de sus implicaciones y contribuciones para el análisis e interpretación de ciertos procesos sociales en marcha. En este sentido, me interesa destacar aquí dos aspectos que considero no sólo particularmente relevantes en las sociedades latinoamericanas contemporáneas, sino que además se encuentran enclavados en el corazón mismo de los procesos de segregación urbana -aunque no siempre se lo perciba así-. Estos dos temas son: el de "la sociabilidad urbana” y el de "la dimensión simbólica de la segregación".

Como señalé en párrafos anteriores, la segregación urbana se inserta, de distintas formas, en procesos de diferenciación, desigualdad y/o exclusión. Y si bien cada uno de estos conceptos hace referencia a procesos distintos, todos ellos tienen en común que expresan de distintas maneras un proceso esencialmente relacional. Más aún, no se trata de una condición relacional cualquiera, y más específicamente no se trata de una relación entre iguales; en los tres casos se trata de una relación entre "nosotros" y "otros": otros diferentes, otros con más o menos oportunidades, otros integrados o excluidos, u otros en los que se superponen más de una de estas condiciones.

Con sociabilidad me refiero precisamente a la problematización de la relación e interacción con los "otros", y esto hace referencia al mismo proceso de construcción de la "otredad", su naturalización que la hace pertenecer al "orden de las cosas" y expresarse en aspectos empíricamente reconocibles ${ }^{2}$, pero también a las formas y actitudes hacia el encuentro o desencuentro con el otro. Reguillo (2005) ha identificado la sociabilidad urbana como una de las vertientes temáticas más importantes para la antropología urbana contemporánea, la cual, para esta

\footnotetext{
2 Tal como señala García Canclini "es necesario considerar a la otredad como una construcción imaginada que -a la vez- se arraiga en divergencias interculturales empíricamente observables” (2005, p. 213).
} 
autora, se vincula con la emergencia de nuevos malestares en la ciudad y la reconfiguración de la noción de ciudadanía. En efecto, distintos procesos y tendencias seculares y estructurales que confluyeron en nuestro tiempo y cuyo abordaje escapa a las posibilidades de este texto, han conducido a una creciente fragmentación identitaria y al debilitamiento de viejas y aglutinadoras categorías, a la individualización de los riesgos pero también de las oportunidades, y al abandono de sectores de la población entrampados en procesos de acumulación de desventajas, que además tienden a ser estigmatizados. Los diferentes, los desiguales, los excluidos, que pueden estar representados por los mismos sujetos en distintas combinaciones, se multiplican y están cada vez más cerca. La pregunta que emerge de manera inevitable es entonces, parafraseando a Alain Touraine, si "podemos vivir juntos", y más aún cómo experiencialmente se vive en y con la "otredad".

La segregación urbana debe enmarcarse en esta discusión en torno a la sociabilidad urbana contemporánea. Duhau, se pregunta qué es lo que se trata de entender cuando se estudia la división social del espacio, y entre los cuatro temas que destaca menciona como uno de ellos los efectos y consecuencias sobre fenómenos sociales tales como "la posibilidad de interacción entre grupos sociales diferentes, grados de aceptación de la vecindad o proximidad espacial de quienes son socialmente diferentes, niveles de tensión o conflicto entre diferentes grupos y estratos sociales, diferencias en las posibilidades de acceso a bienes urbanos, etc."3 (Duhau, 2003a, p. 179). Sin forzar las interpretaciones, creo que esta última apreciación forma parte de lo que aquí he denominado sociabilidad urbana. El tema en cuestión es cómo la estructura espacial, la división social del espacio urbano, refleja, condensa, y retroalimenta una estructura social compleja en la que coexisten y se combinan procesos de diferenciación, desigualdad, y exclusión. Pero más aún, cómo la organización del espacio urbano, la distribución en él de sujetos socialmente posicionados, condiciona y es condicionada, refleja y responde, a los desafíos que plantea esta nueva sociabilidad urbana, a la construcción e interacción, al encuentro y la evitación con el "otro".

El análisis de los procesos de segregación urbana resulta clave para construir una respuesta a estas interrogantes. Sin embargo, los estudios sobre segregación tienden a concentrarse exclusivamente en sus dimensiones objetivas, lo cual por un lado ha limitado el análisis, pero además, y más importante aún, ha generado innumerables problemas para interpretar la relación entre la estructura espacial y la estructura social. Para explotar en todas sus potencialidades el análisis, debemos no sólo incorporar una dimensión simbólica de la segregación sino también, y fundamentalmente, asumir una relación compleja entre ambas dimensiones. Esto significa, básicamente, evitar pensar a ambas dimensiones ligadas por una relación unicausal y/o unidireccional. Aunque efectivamente existe una relación recíproca y de retroalimentación entre ambas, se trata de una relación compleja, en la que sus fronteras no siempre coinciden (pueden superponerse de múltiples formas distintas), y en la que una no puede considerarse ni determinante ni epifenómeno de la otra. Tal como lo señala Bourdieu (2002, p. 123) "si el hábitat contribuye a formar el hábitus, éste hace lo mismo con aquel, a través de los usos sociales, más o menos adecuados, que induce a darle."

3 Las cursivas son mías, y no están presentes en el original. 
La segregación urbana no se agota en su dimensión objetiva. Ella es el resultado de esta relación compleja entre sus dimensiones objetiva y simbólica; es un producto nuevo, sui-generis, que no necesariamente coincide con una u otra. Estamos acostumbrados a pensar que un espacio con indicadores objetivos de alta segregación, debe coincidir con formas duras de segregación simbólica, o espacios de escasa segregación objetiva (o a muy pequeña escala) entonces deben ir acompañados de una escasa segregación simbólica.

Algunos autores han explorado la centralidad de distintos aspectos de esta dimensión simbólica en los procesos de segregación urbana. La mayoría de ellos se han concentrado en uno de estos aspectos: los estigmas territoriales (Wacquant, 2001), los cuales si bien son particularmente relevantes y condicionantes de las formas que adquiere la sociabilidad urbana, no agotan la dimensión simbólica de la segregación. Barbosa (2001) señala que los aspectos simbólicos de la segregación forman parte de una dimensión que en este campo de estudio aún requiere ser mejor entendida y más profundamente abordada. Al referirse a estos aspectos la autora señala:

"Los determinantes simbólicos se refieren tanto a los patrones culturales como a los elementos psicológicos que afectan los procesos de segregación espacial a través de las percepciones sobre los individuos y las identidades colectivas. Estos determinantes actúan tanto en grupos que pretenden segregarse, ya sea porque lo ven como algo favorable para defenderse colectivamente o porque lo ven como un símbolo de status, como también en grupos que inducen la segregación de otros, a los que consideran no-deseables" (Barbosa, 2001, p. 12).

En un sentido similar, Sabatini, Cáceres y Cerda (2001) añaden a las dimensiones objetivas de la segregación (representadas por la concentración y homogeneidad social) una dimensión "subjetiva" a la cual asocian con el prestigio o desprestigio social de las distintas áreas o barrios de cada ciudad, y concomitantemente de las personas y familias que los habitan. De igual manera los autores reconocen que se trata de un aspecto central aunque al mismo tiempo uno de los menos estudiados. En ambos casos, esta dimensión simbólica, para Barbosa, o subjetiva para Sabatini y sus colegas, se constituye en una fuerza activa de segregación y al mismo tiempo en condicionante de los encuentros o desencuentros con los otros.

La dimensión simbólica de la segregación urbana hace referencia entonces a un proceso de construcción social por medio del cual se construyen, atribuyen y aceptan intersubjetivamente ciertos sentidos al y sobre el espacio. Este proceso de construcción social de sentidos es sin duda condicionado por las dimensiones objetivas de la segregación urbana; así por ejemplo, las áreas con alta concentración de pobres pueden asociarse con una serie de estigmas, temores, valoraciones, etc. Pero de igual manera, los sentidos socialmente construidos sobre ciertos espacios y sectores sociales, que logran cierta preeminencia en el imaginario social, pueden resignificar o significar de diversas formas aquellas dimensiones objetivas. La segregación urbana en este sentido amplio, es decir como resultado sui generis de la interacción entre las distancias espaciales que unen y separan a diferentes, desiguales, o excluidos, por un lado, y la construcción imaginada del "otro" y su hábitat, por otro, contribuye así a des-socializar o naturalizar la estructura social y brinda herramientas para resolver, de distintas formas posibles, la coexistencia con los "otros" en un mismo espacio urbano. 


\section{La segregación espacial en México o la coexistencia de mundos aislados}

En este punto presento algunos argumentos e insumos que contribuyen a construir una interpretación plausible respecto al sentido que adquiere la segregación urbana en la Ciudad de México ${ }^{4}$. Para avanzar en esta tarea resulta necesario considerar algunas de las ideas planteadas más arriba, en particular la forma en que se da la relación entre estructura social y estructura espacial, y la forma en que se da la relación entre las dimensiones objetiva y simbólica de la segregación.

La estructura social mexicana se caracteriza por una profunda desigualdad en las condiciones de vida de la población, la cual se expresa en múltiples y diversos indicadores, tanto referentes a la distribución del ingreso, los niveles educativos, la inserción en el mercado de trabajo, el acceso a servicios de salud, y la seguridad social, entre otros. En el contexto latinoamericano, el cual constituye la región más desigual del mundo, México se ubica entre aquellos países donde estas disparidades alcanzan sus niveles más altos. El índice de Gini para la distribución del ingreso es de 0.52 , el decil más rico de la población concentra el 35\% de los ingresos, mientras que el 40\% más pobre sólo recibía el 16\% (CEPAL, 2005); México presenta la irritante paradoja de contar con connacionales entre las personas más ricas del mundo al mismo tiempo que cerca de la mitad de su población vive en condiciones de pobreza. Esto ha llevado a hablar de una clara polarización de la estructura social entre una ciudadanía de primera y de segunda clase.

Un rasgo distintivo de esta estructura ha sido además que a pesar de los innumerables logros y avances que se han alcanzado en el transcurso de la segunda mitad del siglo pasado, particularmente durante el período de industrialización por sustitución de importaciones -o período estabilizador, como se le llama en México-, la profunda desigualdad no sólo persiste sino que tiene una larga data. Es decir, la interacción de los agentes en el espacio urbano está profundamente tamizada por una arraigada desigualdad en la estructura social que ha filtrado de manera profunda la estructura espacial (Bayón, 2006; Reygadas, 2008). La polarización social, la segregación residencial y la fragmentación de la estructura urbana no pueden considerarse novedades emergentes de los últimos años (Duhau, 2003a), con lo cual la integración de las dimensiones objetiva y simbólica adquiere características especiales. Esta trayectoria de la estructura social mexicana dota de especificidades propias a diversos fenómenos y procesos sociales, que no pueden pasarse por alto a la hora del análisis (Bayón, 2006). En este sentido y refiriéndose a la Ciudad de México, Duhau y Giglia (2004) señalan por ejemplo, algo que comparto plenamente: a diferencia de la pobreza urbana del mundo desarrollado, al ser aquí mayoritaria, no parece tener el mismo impacto en la constitución de la subjetividad, lo cual también podríamos decir respecto a la larga persistencia de una estructura social desigual y polarizada.

\footnotetext{
4 Al decir Ciudad de México me refiero al área metropolitana conocida como Zona Metropolitana de la Ciudad de México (ZMCM), la cual constituye el núcleo demográfico, económico, social y político más importante del país. Abarca las 16 delegaciones del Distrito Federal y 35 municipios del Estado de México. Esta última delimitación corresponde a la realizada por el INEGI a partir de la actualización de la cartografía censal del 2000 (Ver INEGI, 2005).
} 
En la ZMCM, como suele suceder en muchas de las grandes metrópolis latinoamericanas, esta estructura social encuentra expresión en profundos contrastes tanto en el paisaje urbano de la ciudad como en las condiciones de vida de su población. Sin embargo, esta estructura social tan fuertemente arraigada, no parece encontrar su contraparte en una estructura espacial igualmente polarizada. Al menos los distintos indicadores de segregación urbana no parecen mostrarlo así, aunque este es un tema en discusión. En términos generales, una visión de conjunto de esta gran zona metropolitana muestra que hacia el oriente de la ciudad se extiende un amplio espacio integrado por delegaciones y municipios en los que residen los sectores más pobres de la población, y en los cuales los más diversos indicadores relativos a las condiciones de vida predominantes muestran los mayores rezagos; de manera contrastante, la zona norponiente y centro de la ciudad, y algunas áreas del sur, son el lugar de residencia de los sectores más privilegiados, además de mostrar (más allá de islas de altísima exclusividad) los niveles de ingreso, educación, infraestructura urbana, etc., más altos de todo este conglomerado urbano (y de los más altos del país). Ahora bien, esta percepción representa casi una fotografía aérea de la ciudad, y es bien sabido que la apreciación del nivel de segregación urbana depende de la escala de análisis que se considere.

En efecto, el análisis a una escala mucho más pequeña muestra que esta primera imagen de polarización comienza por lo menos a debilitarse, y emerge una estructura espacial en ciertos aspectos más fragmentada. En un artículo reciente que refleja parte de los resultados de una amplia investigación sobre la estructura espacial de la Ciudad de México, Parnreiter (2005) señala que la hipótesis de una clara polarización de la estructura urbana es insostenible, idea que también ha sido sostenida por Rubalcava y Schteingart (2000) a partir de datos del Censo de 1990. Estos trabajos muestran, al igual que otros, que sectores de clase media e incluso baja, también se asientan en áreas del centro y oeste de la ciudad donde tradicionalmente han residido las clases privilegiadas. Es decir, si bien puede seguirse un patrón de residencia de las clases altas, que se extiende por el nor-poniente y centro de la ciudad (alcanzando algunas colonias del sur), este no es un cinturón cerrado sino que constituye más bien una sucesión de islotes rodeados de sectores de clase media e incluso baja. Panreiter concluye:

"Los resultados de estas investigaciones sobre estructura de ingresos, construcción y desarrollo de los precios del suelo demuestran, sobre una amplia base empírica que la Ciudad de México no es de ninguna manera una ciudad polarizada. Es verdad que del oeste hacia el este existen grandes desniveles con respecto a los ingresos, al valor de la vivienda y al precio del suelo, y por tanto una preferencia espacial de las clases altas por las zonas del centro y del oeste de la ciudad, mientras que en la zona este prácticamente no viven clases altas o medias. Sin embargo los resultados empíricos muestran claramente: a) que si bien la clase alta se encuentra concentrada en algunas pocas colonias, estas se encuentran distribuidas en muchas delegaciones y municipios del centro, noroeste, oeste, sudoeste y sur de la ciudad, b) que los pobres se encuentran dispersos por toda la ciudad". (Parnreiter, 2005, p. 20).

Con base en los resultados de los censos de los años 1990 y 2000, y a través de un ejercicio estadístico que permite calcular los llamados "índices de exposición”, Ariza y Solís (2005) evaluaron la probabilidad de contactos a partir de su lugar de residencia entre sectores sociales opuestos en términos de sus niveles de ingreso, educación, e inserción en el mercado de trabajo. 
Los hallazgos de estos autores confirman de alguna manera lo que venían señalando los trabajos reseñados previamente. Los individuos con bajos ingresos tienen una altísima probabilidad (superior al 90\%) de interactuar con otros de su misma condición, mientras que es mínima la de encontrarse con individuos de altos ingresos. Sin embargo, la situación para estos últimos no parece ser la misma, al menos estadísticamente. Las probabilidades de que los sectores privilegiados en términos de ingreso interactúen con personas de su misma condición fluctúan entre el $20 \%$ y el $30 \%$, mientras que las de cruzarse con personas de bajos ingresos alcanzan valores del 70 al 80\% (Ariza y Solís, 2005). Algo similar ocurre al tomar en cuenta las otras variables (educación y ocupación). Es decir, mientras parecería existir un alto aislamiento de los sectores más desfavorecidos de la ciudad, y una mayor homogeneidad social de sus áreas de residencia, no ocurriría lo mismo con los sectores privilegiados, quienes residirían en áreas socialmente más heterogéneas, que favorecería el encuentro con los “otros".

Ahora bien: ¿Cuál es el significado de estas probabilidades de encuentro o desencuentro? ¿Cuáles sus implicaciones? ¿Existe interacción, reconocimiento mutuo, sentido de una misma pertenencia? Es decir, ahora debemos preguntarnos por la calidad de los encuentros y relaciones, o en términos de Honneth (1997) por la calidad moral del reconocimiento, aspecto clave de la noción de ciudadanía.

Por un lado, puede decirse que los sectores más desfavorecidos si bien tienden a concentrarse en áreas específicas de la ciudad homogéneamente pobres, no permanecen "encerrados" allí; muchos de ellos, si no la mayoría, trabajan en otras zonas de la ciudad, con frecuencia en las ocupadas por las clases privilegiadas, las cuales, como ha mostrado Duhau (2003a), suelen ser las más demandantes de mano de obra proveniente de otras áreas. El servicio de comunicación y transporte, en gran medida de tipo informal pero también con una amplia red de metro y transporte terrestre formal subvencionado por el Estado, hace posible grandes y largos desplazamientos por la ciudad, lo cual ha sido una característica destacada de la vida cotidiana de los sectores populares en México (Selby et al., 1990). Es decir, el residir en zonas homogéneamente pobres no necesariamente descarta la posibilidad de encuentros con miembros de las clases privilegiadas, aunque es cierto que circunstanciales y muy poco densos.

Por otro lado, el que las clases privilegiadas vivan rodeadas, inclusive con una altísima proximidad, de sectores pobres, no significa que el encuentro, aunque con mucha probabilidad, efectivamente ocurra. Hiernaux, por ejemplo, señala que: "los jóvenes de esos barrios residenciales no conocen los barrios pobres, se desplazan de las universidades o de sus escuelas de alto nivel a sus casas, se pasean y compran en los centros comerciales y en caso de necesidad serán atendidos por médicos de hospitales privados; sus relaciones sociales no se extienden más allá de esos espacios segregados; allá viven, se educan, toman sus tiempos libres y casi seguramente allá se casarán, para vivir a su vez en los mismos ámbitos” (Hiernaux, 1999, p. 13). Es decir, el residir en zonas que a cierta escala resultan socialmente heterogéneas no asegura la interacción con los sectores más pobres, más allá de algún que otro encuentro casual e intrascendente. 
En otras palabras, las dimensiones objetiva y simbólica no necesariamente se corresponden. El nivel de aislamiento espacial no necesariamente se condice con el nivel de aislamiento social ${ }^{5}$. Esto es otra forma de decir y destacar que lo que realmente importa no es (sólo) la posibilidad del encuentro, de la relación con el otro, sino la calidady densidad de esos encuentros y relaciones entre "otros"'.

Aunque las características de la estructura espacial dejen abierta la posibilidad de encuentros entre diferentes y desiguales, e incluso considerando que muchos de estos encuentros, circunstanciales e intrascendentes, efectivamente ocurren, la estructura social fuertemente polarizada y arraigada en la sociedad mexicana, encuentra en la ciudad de México su expresión en un profundo aislamiento social tanto de los sectores más pobres como de las clases más privilegiadas. Se trata de la coexistencia de dos mundos aislados. Idea que ha sido expresada por otros autores como Duhau (2003b) al señalar que en la Ciudad de México se da una co-existencia, sin co-presencia, de los sectores populares con las clases medias y altas, o por Hiernaux (1999), quien sostiene que sería posible hablar de dos ciudades, cada cual con su propia lógica.

Una de las preguntas más intrigantes que se deriva del panorama descrito hasta aquí es entonces cómo es posible esta coexistencia en un mismo espacio urbano, coexistencia no sólo de sectores de la población diferentes, sino también profundamente desiguales; o bien, de manera menos provocadora, podríamos preguntarnos cómo se experimenta, cómo se procesa en el devenir de la vida cotidiana, esta coexistencia. Nos situamos nuevamente en la esfera de la sociabilidad urbana.

Parte de la respuesta reside en un aspecto objetivo de segregación, tal vez difícilmente medible, que consiste en el hecho de la existencia de: por un lado, grandes zonas homogéneamente pobres, y por otro, pequeñas islas de altísima exclusividad, desparramadas en ciertas áreas de la ciudad. Más allá de que los indicadores cuantitativos puedan o no reflejarlo, estos dos espacios constituyen verdaderos mundos aislados. Tal como señala Parnreiter (2005, p. 20), "pobres y ricos podrían en un futuro vivir juntos con mayor frecuencia, en espacios urbanos más pequeños; sin embargo, esto no debe ser precipitadamente entendido como una mayor mezcla entre las diferentes clases: las diferencias sociales aumentan, y la construcción de los barrios cerrados indica que cada vez se levantan más barreras físicas entre los diferentes grupos de la población”.

\footnotetext{
5 Este es un aspecto muy relevante, y que sin embargo ha recibido muy poca atención. Los teóricos que reflexionan sobre los rasgos definitorios de nuestro tiempo, de la modernidad tardía, reflexiva, o líquida, pero también incluso de la globalización, han puesto énfasis en la reconfiguración de la dimensión espacial y temporal, y en particular de la escisión de ambas dimensiones; sin embargo, así como la equivalencia entre tiempo y espacio se ha debilitado, también lo ha hecho la relación entre el tiempo y lo social, y el espacio y lo social, sin que esto atrajera el mismo interés. Las distancias espacial, temporal y social, asumen nuevas articulaciones muy diferentes a una correspondencia directa, como tradicionalmente habían puesto en evidencia diversos estudios antropológicos.

6 Para decirlo con un ejemplo, la calidad de las relaciones hace referencia a esa cualidad que permite distinguir entre el encuentro de un profesional médico que al subir a su camioneta se enfrenta con un obrero de la construcción que espera el autobús, del encuentro del médico y el albañil en los asientos colindantes de un mismo transporte público que ambos usan habitualmente, aunque en ninguno de los dos casos medie una palabra entre ellos.
} 
Pero otra parte de la respuesta, tan o más importante que la anterior, reside en la dimensión simbólica de la segregación. Para decirlo en términos más directos, existen espacios restringidos, "prohibidos", para uno u otro sector de la población, que no requieren de barreras físicas, pero que están separados por espesas murallas simbólicas. Además de estas barreras simbólicas tan irritantemente visibles, dentro de estos espacios de residencia, de esparcimiento, de consumo..., de sociabilidad, priman lógicas diferentes. La coexistencia de mundos tan diferentes, tan desiguales, no puede entenderse sin esta dimensión simbólica que fragmenta la estructura espacial y la estructura social.

Los sectores privilegiados pueden vivir rodeados de pobres, y encontrarse con ellos con cierta frecuencia; sin embargo, la Encuesta Nacional sobre Discriminación realizada en México en el año 2005 nos dice que el 60\% de los encuestados reconoce sentir temor de acercarse a los pobres únicamente por su aspecto. Encuentros entre "otros desiguales" sí, pero teñidos por el miedo, la desconfianza, y seguramente el rechazo. Uno de los jóvenes entrevistados en Valle de Chalco, consultado acerca de las características de su colonia en relación con otras ocupadas por sectores de clase media-alta y alta, se refería de manera transparente a esta coexistencia de mundos aislados.

"No pus, ellos la verían feo ¿no?, como todo. Sí, te discriminarían muy feo, así como que: “¡no! ¡A poco aquí vives!” y tú sabes... no sé, hasta pena te daría ¿̨no?, de que unos jóvenes así estén ahí echando de menos a tu colonia cuando viven en otra. No sé... tienen razón porque ellos tienen... no sé... mejores oportunidades y la vida social de allá es mejor y desgraciadamente aquí no lo es... pus ni modo, te tienes que adaptar a las cosas”. ¿Y tú nunca has tenido... o nunca has interactuado con alguna persona que tenga más dinero o que viva en alguna de esas colonias? "No la verdad es que no. Siempre... ¿cómo te explico? siempre son como que más así ¿̨no?, ni se acercan a ti o yo que sé..., ellos en su círculo civil y nosotros en nuestro círculo civil y... como que no interactúan, no”. (Emilio, 17 años, Valle de Chalco)

En una crítica desde la antropología, García Canclini (1995) señaló hace ya más de una década atrás los riesgos de ver una sola ciudad, en el sentido de una ciudad unívoca, y en cambio sugería pensarla como un "rompecabezas desarmado". Las piezas de este rompecabezas, al menos algunas de ellas, representan espacios con lógicas diferentes, y no sólo eso, sino también espacios inexistentes. Utilizando términos de Bauman son espacios vacíos, vacíos de sentido, es decir el tratamiento más radical que puede dársele a las diferencias, y al mismo tiempo disolvente de la otredad.

"Los espacios vacíos están primordialmente vacíos de sentido. No es que sean insignificantes por estar vacíos, sino que, por no tener sentido y porque se cree que no pueden tenerlo, son considerados vacíos... Son vacíos los lugares en los que no entramos y en los que nos sentiríamos perdidos y vulnerables, sorprendidos, alarmados, y un poco asustados ante la vista de otros seres humanos" (Bauman, 2004, pp. 111-113).

A pesar de la cercanía, de la proximidad, de los millones que vivimos en un mismo espacio, la Ciudad de México está llena de espacios vacíos. Y esto es lo mismo que decir, que esos espacios, vacíos para unos, son significados y vividos por otros. Este aspecto es fundamental: 
la coexistencia de mundos tan diferentes, pero fundamentalmente tan desiguales y al mismo tiempo tan próximos y cercanos, sólo es posible de sostener a través de este doble mecanismo de presencia de lógicas diferentes que se desconocen mutuamente. Chimaluhacán y Santa $\mathrm{Fe}$, Valle de Chalco e Inter Lomas, son recíprocamente espacios vacíos, que los constituyen simultáneamente y respectivamente en el único mundo [posible]. Se trata de un feroz aniquilamiento de la "otredad", que incluso impide ver al otro cuando se le tiene enfrente.

\section{El reconocimiento de los estigmas territoriales}

En Parias Urbanos, Loïc Wacquant (2001) señala que hoy cualquier estudio sociológico sobre la "nueva" pobreza debe comenzar con la mención del poderoso estigma asociado a la residencia en los espacios restringidos y segregados. Los estigmas territoriales no son sólo fuente de desventajas, sino al mismo tiempo instrumentos de diferenciación social y, sobre todo, expresión de una violencia simbólica que reproduce y consolida las relaciones de poder y las desigualdades de la estructura social. Por un lado, los estigmas asociados con los espacios ocupados hacen presente, remarcan, pero también establecen y afirman que no somos todos iguales. Lo significativo es que estos estigmas territoriales crean la ilusión de estar escindidos de la estructura social, y con ello plantean una desigualdad naturalizada. No es una desigualdad de mercado, de derechos, o de oportunidades, se presenta como una desigualdad reificada, natural.

Tiende a predominar, sin embargo, tanto en los análisis como en los portadores de los estigmas territoriales, la percepción de que estos forman parte de un inconsciente colectivo (en términos durkheimianos) parcializado, diferenciado. Es decir, la impresión dominante es que las diversas estigmatizaciones están perfectamente distribuidas en concordancia con la segregación del espacio urbano, y por lo tanto que los sujetos depositarios de estos estigmas no son conscientes de ellos, sino que sólo son parte del inconsciente colectivo de nosotros. Este supuesto asumido, inherente a los estigmas territoriales, tiene un efecto tranquilizador, hacen menos violenta y visible, la presencia y ejercicio de esta violencia simbólica. Las entrevistas nos muestran, sin embargo, que la violencia simbólica ejercida como violencia inadvertida, no es en realidad inadvertida.

¿Tú cómo crees que un chavo de Coyoacán, o Benito Juárez, ve esta colonia en particular? "Pues fíjate que conozco muchas personas que vienen de por allá y la ven este... malísima eh, la ven pésima, por este... por la delincuencia más que nada". ¿Qué dicen? "Pues que es muy conflictiva o cualquier cosa, así es de la manera que la ven, o sea muy conflictiva la ven, que hay mucho pandillero por aquí. Pues sienten ellos que es muy peligrosa, hay veces, hay ocasiones que este no quieren ni entrar aquí a la colonia”. ¿Qué te comentan? "Que pues este pus ‘¿cómo puedes vivir en esta colonia, si hay tanto delincuente?’ cosas así por el estilo”. ¿Y tú que piensas de ellos? "Pues... a la vez pienso que tienen mucha razón, por la situación que se ha venido dando en la colonia” (Rubén, 22 años, Iztapalapa).

En prácticamente todas las entrevistas los jóvenes dejaron ver claramente su conocimiento de los estigmas territoriales que pesan sobre sus propias colonias y sus residentes. Y en cierta medida, aunque con dudas, también ellos dejan ver cierta reificación de las desigualdades expresadas en dichos estigmas. Este reconocimiento de los estigmas es particularmente relevante como 
dato antropológico en la medida que nos permite reinterpretar la interacción social. Pone al descubierto la ilusión de una violencia simbólica silenciosa, que no por ello es inadvertida, y que por ende se filtra en todo encuentro, en toda interacción. La interacción, en tanto puesta en escena de una actuación, como simulación (Goffman, 1988), se apoya en dicha ilusión, pero no puede hacerla desaparecer. Es decir, aunque hagamos "como si no", pretendiendo que el otro desconociera los estigmas que cargamos sobre él, el reconocimiento recíproco de los estigmas mutuos está presente y condiciona los encuentros e interacciones.

Las entrevistas citadas hasta aquí, muestran además otro denominador común. Los estigmas territoriales, al menos los reconocidos, tienden a priorizar un aspecto: el de la inseguridad. El 24 de diciembre de 2004, un artículo de una página completa en un periódico de circulación nacional, titulaba con letra de molde y gran tamaño "En Iztapalapa dos de cada tres jóvenes viven en la marginalidad: Arquidiócesis"; en el subtítulo se explayaba "En un alto indice, están expuestos a la droga, la violencia y el delito, según diagnóstico". En efecto, las zonas en las que he realizado el trabajo de campo presentan serios problemas delictivos y altos índices de criminalidad, frecuentemente reproducidos en la prensa y diversos medios de comunicación. Sobre estos indicadores se apoyan muchos de los estigmas que se construyen en torno a estas áreas; sin embargo, los estigmas se basan en la generalización a partir de la asociación, y este es el punto que me interesa destacar aquí. Tal como señalan diversos estudios, se observa una estigmatización criminalizante de la pobreza, y en particular de ciertos espacios urbanos (áreas periféricas) y ciertos grupos etáreos (los jóvenes de sectores populares). Tanto los espacios urbanos como los jóvenes son igualmente objeto de un mismo proceso de estigmatización. Estigmas territoriales en un caso, estigmas etáreos en el otro. Su combinación se constituye en una pesada y doble carga para los jóvenes de los sectores populares.

La configuración de los miedos que la sociedad experimenta ante ciertos grupos y espacios sociales tiene una estrecha vinculación con ese discurso de los medios que, de manera simplista, etiqueta y marca a los sujetos de los cuales habla. Mediante estas operaciones, ser joven equivale a ser "peligroso", "drogadicto o marihuana", "violento"; se recurre también a la descripción de ciertos rasgos raciales o de apariencia para construir las notas. Entonces ser un joven de los barrios periféricos o de los sectores marginales se traduce en ser "violento", "vago", "ladrón", "drogadicto", "malviviente" y "asesino" en potencia (Reguillo, 2000, pp. 155-56).

Castel (2004) ha bautizado a este proceso como el retorno de las clases peligrosas, al cual lo asocia con la inseguridad social que caracteriza a la sociedad contemporánea. Dicho en otros términos, los estigmas territoriales asociados con la inseguridad, la delincuencia, y la violencia contribuyen a la construcción de clases peligrosas, en las cuales se transfieren y depositan las ansiedades, temores y tensiones derivadas de una inseguridad social que trasciende con creces la inseguridad civil.

La inseguridad social y la inseguridad civil se superponen aquí y se alimentan recíprocamente. Pero sobre la base de estas constataciones que no tienen nada de idílico, la diabolización de la cuestión de los suburbios pobres, y particularmente la estigmatización de los jóvenes de esos suburbios a la cual se asiste hoy en día, tiene que ver con un proceso de desplazamiento de la conflictividad social que podría representar perfectamente un dato permanente de la 
problemática de la inseguridad. "La escenificación de la situación de los suburbios pobres como abscesos donde está fijada la inseguridad, a la cual colaboran el poder político, los medios y una amplia parte de la opinión pública, es de alguna manera el retorno de las clases peligrosas, es decir, la cristalización en grupos particulares, situados en los márgenes, de todas las amenazas que entraña en sí una sociedad... Pero estas estrategias, sobre todo si están bien escenificadas y si se les persigue con determinación, al menos tienen el mérito de mostrar que se hace algo (no se es laxista) sin tener que hacerse cargo de cuestiones más difíciles y exigentes tales como, por ejemplo, el desempleo, las desigualdades sociales, el racismo, que también están en el origen del sentimiento de inseguridad" (Castel, 2004, pp. 70-72).

Cuando estos mismos jóvenes dan sus opiniones respecto a sus propias colonias, vuelven a trazar una línea entre ellos y los otros. En este planteamiento se destacan dos elementos significativos. El primero de ellos, es que la primera y más espontánea descripción que hacen de su espacio parece plantearse como una respuesta, o más aun, como una negación de los estigmas territoriales que pesan sobre sus colonias. El rasgo que se privilegia es la tranquilidad, la pacificidad incluso, de sus entornos. El segundo elemento significativo es, sin embargo, una relativización de estos atributos de su colonia. En efecto, los mismos jóvenes reconocen que sus colonias son tranquilas para ellos, pero que pueden constituir lugares peligrosos para "otros".

"Ya como que le dieron una famita de que pues de lo peor acá, pero pues es que no saben lo que es vivir acá". ¿Por qué? ¿A ver, cómo es vivir acá? "Es tranquilo... o sea, así como dicen en las noticias que matan... bueno que mataron a este y al otro y al otro, o sea sí, pero no siempre. Cada mes, cada dos meses matan a alguien. Pero es tranquilo, o sea bueno más que nada no sé si sea porque ya nos conozcan a los que vivimos en la colonia porque a nosotros no nos hacen nada, hemos pasado dos, tres de la mañana y tranquilo” (Inés, 27 años, Nezahualcoyotl).

¿Entonces es tranquilo vivir aqui? "Sî". ¿Ypor qué se habla tanto de que es tan peligroso? "Pus no o sea ya no' más es la pura fama que quedó aquí porque pus ya... casi no; dicen que crea fama y échate a dormir, pero no, aquí ya no hay nada de eso, dicen que aquí es el barrio más pesado pero no". ¿Se puede decir que es lo mismo que vivir en Coyoacán o Tlalpan, o es más peligroso? "Bueno, no, no tanto así; o sea, sí es un poco peligroso aquí pero pus es que es la suerte ¿no?" Si yo me voy ahora a las seis o siete de la tarde y quiero irme caminando hasta el metro... ¿es peligroso o no? "Pues algo, porque por aquí sí está un poco pesadita”. ¿Qué me puede pasar? "Pues que lo asalten, que le quiten su dinero... Porque pus... como no lo conocen y pus cuando ven ahora si que, como los animales, ven carne nueva y pus órale sobre él” (Leo, 18 años, Iztapalapa).

No sabemos, e incluso puede resultar imposible de medir, cuánto de estas percepciones se apoyan en experiencias concretas y datos objetivos de hechos de inseguridad hacia los extraños, y cuánto en una autorreproducción y expansión de esta imagen pública de la colonia con independencia de su verdadera situación. Pero, más allá de cuáles sean sus fuentes (y en cuánto), los estigmas territoriales comienzan a marcar zonas que no es conveniente visitar, en las que no hay que bajar las ventanillas del auto, en las que es mejor moverse en un taxi de sitio, etc., etc.; es decir comienzan a delimitarse un tipo particular de espacios vacíos: zonas prohibidas. 
Las zonas prohibidas no son sino el reverso del aislamiento social' ${ }^{7}$. Distintos sectores sociales reconocen sus propias zonas prohibidas, y esto repercute no sólo en sus respectivas prácticas, sino mucho más importante aún, sus consecuencias se perciben en la estructura social misma: la presencia y encuentros se reducen, la interacción disminuye, el desconocimiento mutuo crece, y los prejuicios y estigmas se constituyen en el principal mecanismo de aproximación al otro.

A partir de estos estigmas se genera y/o profundiza el miedo y la desconfianza hacia el otro. La trascendencia de este debilitamiento de la confianza puede comprenderse en toda su magnitud si tenemos en cuenta su centralidad en la construcción de capital social y cívico y, aunque de manera más indirecta, para el bienestar social y la integración social. La desconfianza basada en el temor a las clases peligrosas limita los encuentros, bloquea la interacción, y atenta contra la cohesión social.

En los estigmas territoriales confluyen diversos aspectos que establecen y reproducen desigualdades en distintos campos. Las clases peligrosas, aunque recubiertas por un estigma criminalizante, representan y condensan además un conjunto de otros estigmas degradantes. Un extenso fragmento de la entrevista con Ignacio, en Iztapalapa, sintetiza buena parte del análisis que he realizado hasta aquí, pero además muestra con toda claridad cómo, en la percepción de estos jóvenes, los estigmas territoriales que pesan sobre ellos y sus lugares de residencia, sintetizan y compactan un conjunto de diversos atributos que van delineando, dando forma, a un espacio y a un actor particular. La expresión, usada por Ignacio, "por allá hay puros nacos" logra la precisión y la síntesis necesaria para dar cuenta de este collage estigmatizante. Vale la pena reproducir esta parte de nuestra conversación.

¿Tú qué crees que otras personas piensan de tu colonia, por ejemplo un chavo que vive en Coyoacán? "Para empezar pus yo creo que con decirle que es en la delegación Iztapalapa 'ay pus allá está muy feo, allá puros rateros y no sé que", pero de la colonia en particular yo creo que dirían lo mismo ¿̇no? que pus allá los nacos o qué sé yo, como mucha gente dice y este... pus sí... pienso que gente así que vive por allá, por esas zonas, diría eso de acá, aunque sea sin visitarla ni nada ¿no? Pero pus diría eso porque la delegación Iztapalapa tiene la fama de ser la... la más cañona y con eso... con que le digas que es en la delegación Iztapalapa pus ya te dicen 'allá no..., está muy feo, que no sé qué y luego si les dices que vives casi en el cerro, pues te van a decir 'no, pus allá no hay nada, seguramente puros caballos o burros todavía habrá ¿̇no?’” ¿Por qué dices que dirían "qquí los nacos"? "Lo que pasa es que pues mucha gente así es... la gente más o menos bien que yo conozco... bueno, no que conozca sino que más bien la he escuchado hablar, pus son gente bien, pus viven allá en puras zonas de ricachones y pus ya na’ más este... se enteran que tú vives por aquí o saben que alguien vive por allá y si les dices 'vente vamos para allă dicen 'ay no! por allá no! por allá hay puros nacos'; ya sabes cómo es la gente ¿̨no?...

Cabe señalar que así como existen zonas prohibidas para ciertos sectores, también las hay para otros. Los centros comerciales y cines de Santa Fe, los barrios residenciales de Las Lomas, o los clubes exclusivos, por mencionar algunos ejemplos, son zonas prohibidas para los sectores populares. Aunque el lector puede pensar que en estos casos existen barreras físicas que impiden el acceso, esto no es siempre así; las barreras simbólicas, sin embargo, están siempre presentes y pueden ser mucho más fuertes y notorias. 
Estratificada la sociedad: entonces están los de abajo, los de en medio y los de arriba, entonces los de arriba siempre se sienten más que los de abajo, por eso te hacen así como que... te discriminan un poco". ¿Y cuál sería la definición de gente bien y de nacos? "Bueno gente bien para mí es gente con dinero ¿no? Gente que por lo menos no tiene preocupaciones económicas y los nacos sería la gente que viven en las zonas así un poco... como aquí ¿no? en la Delegación Iztapalapa, zonas como que muy conflictivas, pues lo contrario de la gente bien. No digo que gente pobre, pero sí gente con menos recursos, tal vez más vulgar que la gente bien porque pus aquí quiéramos o no pus somos más vulgares... tal vez menos educados que la gente con dinero ¿no?” (Ignacio, 19 años, Iztapalapa).

\section{Conclusiones}

He caracterizado a la Ciudad de México por la coexistencia de mundos aislados. Estos mundos pueden estar más o menos reflejados en los diferentes indicadores de segregación urbana existentes, dependiendo incluso de la escala a que se mire el problema. Pero lo importante de destacar aquí es que estos indicadores sólo miden la dimensión objetiva de la segregación urbana, y consideran a la dimensión simbólica como un epifenómeno, casi como una imagen refleja que debe coincidir con aquella. La segregación urbana, en cambio, puede pensarse como resultado (o síntesis en términos dialécticos) de una interacción compleja entre ambas dimensiones. Es en este sentido, que la segregación urbana puede asumir modalidades diferentes, y a veces contrastantes, en distintos contextos nacionales o incluso en distintos espacios urbanos de un mismo país, aun cuando los indicadores (objetivos) de segregación sean similares. En términos diacrónicos, este planteamiento nos permite interpretar de manera más sofisticada los procesos de cambio en los patrones de segregación urbana, que no sólo siguen a los procesos de reconfiguración (objetiva) del espacio urbano, sino que también son resultado de transformaciones en las percepciones, temores, estigmas, etc., con que se le da sentido al espacio urbano y a la presencia de los "otros".

En el caso de la Ciudad de México, la coexistencia de mundos aislados es posible en gran medida debido al aislamiento que los caracteriza recíprocamente, el cual no puede medirse o expresarse sólo en términos objetivos, sino que debe entenderse necesariamente a partir de la dimensión simbólica de la segregación urbana. Esta última constituye un factor clave en la fragmentación de la ciudad, que es consistente con la fragmentación social, y que los indicadores objetivos de segregación nos muestran sólo parcialmente. Sin la dimensión simbólica que nos permite reconocer una ciudad con múltiples espacios vacíos y zonas prohibidas, con fuertes estigmatizaciones territoriales, con diversas lógicas, percepciones y experiencias de la ciudad, no es posible tener una completa comprensión del aislamiento que caracteriza a los mundos en coexistencia. Es decir, la sociabilidad urbana, la forma en que se procesa el encuentro o desencuentro con el otro, está permeada por ambas dimensiones (objetiva y simbólica) de la segregación.

En el análisis previo me concentré no sólo sobre la presencia y contenido de los estigmas que pesan sobre algunas "zonas" y colonias de la Ciudad de México, sino que uno de mis intereses centrales ha sido mostrar que los estigmatizados reconocen plenamente los estigmas de que son objetos. Puede parecer un dato menor, evidente, pero sus implicaciones no lo son. 
Nos permiten pensar de otra manera los encuentros y desencuentros, las interacciones entre "otros", y en este sentido le dan una nueva dimensión al aislamiento social o la coexistencia de mundos aislados. Este aspecto de los estigmas y el contenido de los mismos, nos hablan de la calidad de los encuentros. El trabajo de Honneth nos ha advertido acerca de la centralidad del reconocimiento del otro, y más aún de la calidad de este reconocimiento:

"De allí no hay más que un pequeño paso a la perspectiva ya generalizada que sostiene que la calidad moral de las relaciones sociales no puede ser medida solamente en términos de una justa distribución de bienes materiales; nuestra noción de justicia está también estrechamente ligada a cómo y de qué manera, los individuos se reconocen mutuamente unos a otros" (Honneth, 1997, p. 17).

El reconocimiento de los estigmas afecta de manera clara y profunda lo que Honneth llama la calidad moral de las relaciones sociales, cómo y de qué manera se reconocen mutuamente unos a otros. La dimensión objetiva de la segregación urbana por sí sola no puede dar cuenta de la calidad de los encuentros. Pero una perspectiva más compleja de la segregación urbana que contemple sus dimensiones objetiva y simbólica, nos abre nuevas puertas analíticas. Sólo para cerrar estas reflexiones finales, quisiera sugerir que la coexistencia de mundos aislados, como hipótesis de trabajo, podría contribuir a entender y analizar los problemas de la cohesión social en la sociedad mexicana, y la conflictividad y tensión que caracteriza a los espacios residuales de encuentro en que ambos mundos se cruzan. Las barreras físicas y simbólicas de la segregación y el aislamiento social, no son absolutamente impermeables; sus fisuras dejan ver la fragilidad de la cohesión social y las tensiones desencadenadas por una profunda desigualdad.

\section{Referencias bibliográficas}

Ariza, M. \& Solís. P. (2005). Dinámica de la desigualdad social y la segregación espacial en tres áreas metropolitanas de México. Ponencia presentada en la XXV Conferencia Internacional de Población de la IUSSP, Tours, Francia. Rescatada de http://iussp2005. princeton.edu.

Barbosa, E. (2001). Urban spatial segregation and social differentiation: foundation for a typological analysis. Lincoln Institute of Land Policy, conference paper.

Barry, B. (2002). Social exclusion, social isolation, and the distribution of income. En J. Hills, J. LeGrand \& D. Piachaud (Eds.), Understanding social exclusion. London: Oxford University Press.

Bauman, Z. (2004). Modernidad Líquida. Buenos Aires: F.C.E.

Bayón, M. C. (2006). Precariedad social en México y Argentina: tendencias, expresiones y trayectorias nacionales. Revista de la CEPAL, 88, 133-152.

Bourdieu, P. (2002). Efectos de lugar. En P. Bourdieu (Ed.), La miseria del mundo. Argentina: F.C.E.

Castel, R. (2004). La inseguridad social. Argentina: Manantial.

CEPAL (2005). Panorama social de America Latina 2005. Santiago de Chile: CEPAL.

Duhau, E. \& Giglia, A. (2004). Espacio público, nueva dimensión de lo social, y urbanidad en las colonias populares de la Ciudad de México. Papeles de Población, 10, 41, 167-194.

Duhau, E. (2003a). División social del espacio metropolitano y movilidad residencial. Papeles de Población, 36, 161-210. 
Duhau, E. (2003b). Las megaciudades en el siglo XXI. De la modernidad inconclusa a la crisis del espacio público. En P. Ramírez Kuri (Coord.), Espacio público y reconstrucción de ciudadanía. México: Porrúa y FLACSO México.

García Canclini, N. (1995). Consumidores y ciudadanos. Conflictos multiculturales de la globalización. México: Grijalbo.

García Canclini, N. (2005). Diferentes, desiguales y desconectados. Mapas de la interculturalidad. España: Gedisa.

Goffman, E. (1988). Internados. Ensayos sobre la situación social de los enfermos mentales. Argentina: Amorrrortu Editores.

Hiernaux, D. (1999). Los frutos amargos de la globalización: expansión y reestructuración metropolitana de la Ciudad de México. EURE, 25, 76, 57-78.

Honneth, A. (1997). Recognition and moral obligation. Social Research, 64, 1, 16-35.

INEGI (2005). Cuadernos estadísticos de la Zona Metropolitana de la Ciudad de México. México: INEGI.

Parnreiter, Ch. (2005). Tendencias de desarrollo en las metrópolis latinoamericanas en la era de la globalización: los casos de Ciudad de México y Santiago de Chile. EURE, 31, 92, 5-28.

Reguillo, R. (2005). Ciudad, riesgos y malestares. Hacia una antropología del acontecimiento. En N. García Canclini (Coord.), La antropología urbana en México. México: CONACULTA / UAM / F.C.E.

Reygadas, L. (2008). La apropiación. Destejiendo las redes de la desigualdad. Barcelona: Anthropos.

Rubalcava, R. \& Schteingart, M. (2000). Segregación socio-espacial. En G. Garza (Coord.), La Ciudad de México en el fin del segundo milenio. México: Gobierno del Distrito Federal / COLMEX.

Sabatini, F. (2003). La segregación social del espacio en las ciudades de América Latina. Serie Azul, 35. Santiago: Documentos del Instituto de Estudios Urbanos y Territoriales, Pontificia Universidad Católica de Chile.

Sabatini, F.; Cáceres, G. \& Cerda, J. (2001). Segregación residencial en las principales ciudades chilenas: tendencias de las tres últimas décadas y posibles cursos de acción. EURE, $27,82,21-42$.

Saraví, G. (2007). Nuevas realidades y nuevos enfoques: exclusión social en América Latina. En G. Saraví (Ed.), De la pobreza a la exclusión: continuidades y rupturas de la cuestión social en América Latina. Argentina: CIESAS / Prometeo Libros.

Selby, H.; Murphy, A. \& Lorenzen, S. (1990). The mexican urban household. Estados Unidos: The University of Texas Press.

Touraine, A. (2000). ¿Podremos vivir juntos? México: F.C.E.

Wacquant, L. (2001). Parias urbanos. Marginalidad en la ciudad a comienzos del milenio. Argentina: Manantial.

Wacquant, L. (2002). The zone. En P. Bourdieu (Ed.), La miseria del mundo. Argentina: F.C.E. 